\title{
The Iturin and Fengycin Families of Lipopeptides Are Key Factors in Antagonism of Bacillus subtilis Toward Podosphaera fusca
}

\author{
Diego Romero, ${ }^{1}$ Antonio de Vicente, ${ }^{1}$ Rivo H. Rakotoaly, ${ }^{2}$ Samuel E. Dufour, ${ }^{2}$ Jan-Willem Veening, ${ }^{3}$ \\ Eva Arrebola, ${ }^{1}$ Francisco M. Cazorla, ${ }^{1}$ Oscar P. Kuipers, ${ }^{3}$ Michel Paquot, ${ }^{2}$ and Alejandro Pérez-García ${ }^{1}$ \\ ${ }^{1}$ Departamento de Microbiología, Facultad de Ciencias, Universidad de Málaga, Campus Universitario de Teatinos s/n,

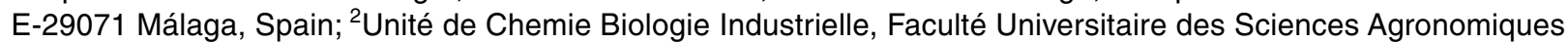 \\ de Gembloux, Passaje des Déportés 2, B-5030 Gembloux, Belgium; ${ }^{3}$ Molecular Genetics Group, Groningen Biomolecular \\ Sciences and Biotechnology Institute, University of Groningen, Kerklaan 30, 9751 NN Haren, The Netherlands
}

Submitted 19 July 2006. Accepted 24 November 2006.

\begin{abstract}
Podosphaera fusca is the main causal agent of cucurbit powdery mildew in Spain. Four Bacillus subtilis strains, UMAF6614, UMAF6619, UMAF6639, and UMAF8561, with proven ability to suppress the disease on melon in detached leaf and seedling assays, were subjected to further analyses to elucidate the mode of action involved in their biocontrol performance. Cell-free supernatants showed antifungal activities very close to those previously reported for vegetative cells. Identification of three lipopeptide antibiotics, surfactin, fengycin, and iturin $A$ or bacillomycin, in butanolic extracts from cell-free culture filtrates of these $B$. subtilis strains pointed out that antibiosis could be a major factor involved in their biocontrol ability. The strong inhibitory effect of purified lipopeptide fractions corresponding to bacillomycin, fengycin, and iturin A on $P$. fusca conidia germination, as well as the in situ detection of these lipopeptides in bacterial-treated melon leaves, provided interesting evidence of their putative involvement in the antagonistic activity. Those results were definitively supported by site-directed mutagenesis analysis, targeted to suppress the biosynthesis of the different lipopeptides. Taken together, our data have allowed us to conclude that the iturin and fengycin families of lipopeptides have a major role in the antagonism of $B$. subtilis toward $P$. fusca.
\end{abstract}

Additional keywords: antifungals, biological control, cucurbits.

Powdery mildew is probably the most common, conspicuous, widespread, and easily recognizable disease of cucurbits, responsible for serious damage to almost all cucurbit crops under both field and greenhouse conditions. As the most characteristic visual symptom, the disease induces development of a whitish, talcum-like, powdery fungal growth on both leaf surfaces, petioles, and stems. Infected leaves usually wither and die, and plants senesce prematurely (Zitter et al. 1996). The disease can be caused by two species Golovinomyces cichoracearum or Podosphaera fusca, obligate biotrophic ectoparasites that induce identical symptoms but can be distinguished easily under light microscopy. In Spain, however, $P$. fusca has been identified as the sole cause of the disease, and

Corresponding author: A. Pérez-García; Telephone: +34-952131890; Fax: +34-952131889; E-mail: aperez@uma.es is responsible for significant yield reductions and increasing production costs (del Pino et al. 2002; Fernández-Ortuño et al. 2006). Application of fungicides is currently the principal practice in most cucurbit crops for managing powdery mildew. However, the increasing problem of fungicide resistance and the consequent control failures (Fernández-Ortuño et al. 2006; McGrath 2001), along with public concern over the hazardous effect of chemicals on the environment, have led growers to explore and develop suitable environmentally friendly alternatives or complements to chemicals, biological control being one way forward (Kiss 2003).

The use of bacterial strains as biological control agents has received great attention because of the ability of such strains to suppress different plant diseases involving a blend of diverse modes of action (Baehler et al. 2006; Cazorla et al 2006; Fogliano et al. 2002; Shoda 2000) and the possibilities to be combined with other control methods (Kondoh et al. 2001; Nofal and Haggag 2006; Omar et al. 2005). Among the most promising candidates for bacterial biocontrol agents are several species of the genus Bacillus, ubiquitously occurring safe microorganisms with proven excellent colonization aptitudes, versatility to protect plants effectively against pathogens (Kloepper et al. 2004; Romero et al. 2004; Shoda 2000), and an outstanding ability to sporulate, which assures their prevalence in the environment and guarantees future suitable formulation strategies (Schallmey et al. 2004).

Several Bacillus strains have been considered to be natural factories of biologically active compounds such as lipopeptides, and the significance of their involvement in plant microbial disease control have been demonstrated (Asaka and Shoda 1996; Emmert and Handelsman 1999). Lipopeptides, oligopeptides synthesized in a nonribosomal manner by large multienzyme complexes, are the most frequent antibiotic compounds produced by bacilli, exhibiting a wide antimicrobial spectrum and exceptional surfactant activities (Magnet-Dana and Peypoux 1994; Vanittanakom et al. 1986; Vater et al. 2002; Vollembroich et al. 1997). These amphiphilic compounds share a common cyclic structure consisting of a $\beta$-amino or $\beta$ hydroxy fatty acid integrated into a peptide moiety. The main differences rely on the amino acid sequence and fatty acid branching, criteria that allow their classification in three families. The iturin family, represented by iturin A, mycosubtilin, and bacillomycin, are heptapeptides with a $\beta$-amino fatty acid which exhibit strong antifungal activity (Duitman et al. 1999; Moyne et al. 2004; Thimon et al. 1995; Tsuge et al. 
2001). Members of the fengycin family, including the related plipastatin, are decapeptides with a $\beta$-hydroxy fatty acid that show unusual properties, such as the presence of ornithine in the peptide portion, and also show antifungal activity, although more specific for filamentous fungi (Steller et al. 1999; Vanittanakom et al. 1986). Finally, the most studied family of lipopeptides, the surfactin family, consists of heptapeptides containing a $\beta$-hydroxy fatty acid with a number of carbon atoms in the range of 13 to 15 , which are possibly the most powerful biosurfactants described, also exhibiting antiviral characteristics; and, although slightly antifungal, they show a strong synergistic action in combination with iturin A (MagnetDana et al. 1992). Furthermore, surfactin seems to be also a key factor in the establishment of stable biofilms, and may inhibit the biofilm formation of other bacteria, thus contributing to the protective action, as shown in Arabidopsis against Pseudomonas syringae pv. tomato (Bais et al. 2004).

In a previous work, we have shown that four Bacillus subtilis strains isolated in our laboratory were able to suppress powdery mildew disease caused by $P$. fusca on melon in both detached leaf and seedling assays, also showing good abilities to colonize melon phylloplane by establishing themselves as cell aggregates (Romero et al. 2004). In order to gain an insight into the underlying mechanisms responsible for the outstanding biocontrol performance of these $B$. subtilis strains, the aims of this study were to evaluate the inhibitory effect of $B$. subtilis cell-free filtrates on $P$. fusca growth, to identify the putative compounds responsible for the antifungal activity of the supernatants, and, finally, to determine the role of these compounds in the antagonism of $B$. subtilis toward P. fusca by analysis of B. subtilis transformants constructed by site-directed mutagenesis of genes involved in the biosynthesis of such compounds.

\section{RESULTS}

\section{Production of antifungal compounds of $B$. subtilis in liquid cultures.}

Relationship between bacterial growth and production of antifungal compounds was analyzed using a growth inhibition assay in 24-well microplates with Botrytis cinerea as the target fungus. Antifungal activity was detected at the transition between exponential and stationary phase of growth, increasing progressively during the later and reaching the highest activity

Table 1. Severity of powdery mildew symptoms and sporulation degree of Podosphaera fusca on melon leaves following treatments with butanolic extracts of cell-free filtrates from Bacillus subtilis antagonistic bacteria ${ }^{\mathrm{x}}$

\begin{tabular}{lrcrc}
\hline & \multicolumn{2}{c}{ Disease symptoms } & \multicolumn{2}{c}{ Sporulation } \\
\cline { 2 - 5 } Treatments & Severity & Reduction $^{\mathbf{y}}$ & Conidia & Reduction $^{\mathbf{z}}$ \\
\hline Untreated & $58 \mathrm{a}$ & $\ldots$ & $1,012 \mathrm{a}$ & $\ldots$ \\
Nutrient broth & $47 \mathrm{a}$ & 19 & $866 \mathrm{a}$ & 14 \\
B. subtilis UMAF6614 & $5 \mathrm{~b}$ & 90 & $124 \mathrm{~b}$ & 88 \\
B. subtilis UMAF6619 & $26 \mathrm{c}$ & 55 & $456 \mathrm{~b}$ & 55 \\
B. subtilis UMAF6639 & $7 \mathrm{~b}$ & 89 & $168 \mathrm{~b}$ & 83 \\
B. subtilis UMAF8561 & $4 \mathrm{~b}$ & 92 & $115 \mathrm{~b}$ & 89 \\
\hline
\end{tabular}

${ }^{\mathrm{x}}$ Severity (assessed as percentage of leaf area covered by powdery mildew) and sporulation (conidia counts $\mathrm{cm}^{-2}$ ) were scored 16 days after treatments. Percentages of disease and sporulation reductions achieved by treatments also are indicated. Data within each column are the means of three independent experiments. Values followed by the same letter are not significantly different at $P=0.05$ according to Fisher's least significant difference test.

${ }^{y}$ Percentage of disease reduction referred to values of leaf area covered by powdery mildew on untreated leaves.

${ }^{\mathrm{z}}$ Percentage of sporulation reduction referred to values of conidia production on untreated leaves. levels after 4 to 5 days of growth, when bacterial populations are composed mainly by spores (data not shown). Once determined the growth stage with the highest level of antifungal activity, cell-free filtrates were tested for their ability to arrest growth of $P$. fusca on melon detached leaves. As revealed by the percentage of leaf area covered by powdery mildew and conidia production (Table 1), butanolic extracts of cell-free filtrates from the four $B$. subtilis strains were able to inhibit growth of $P$. fusca and, in consequence, to suppress the disease. The butanolic extracts from the strains UMAF6614, UMAF6639 and UMAF8561 were highly effective, showing values of disease and sporulation reductions of 85 to $90 \%$. Furthermore, antifungal activity of supernatants was clearly shown by analysis serial dilutions of the cell-free filtrate extracts, which produced a progressive decrease of the disease suppression in such a way that, at 16-fold dilutions, disease reductions of $50 \%$ could be still observed 16 days after application of extracts (Fig. 1).

Biochemical characterization of antagonistic supernatants.

The antifungal activity of cell-free filtrates was subjected to stability tests in order to gain insight into the chemical nature of the responsible compounds (Table 2). The antifungal activ-

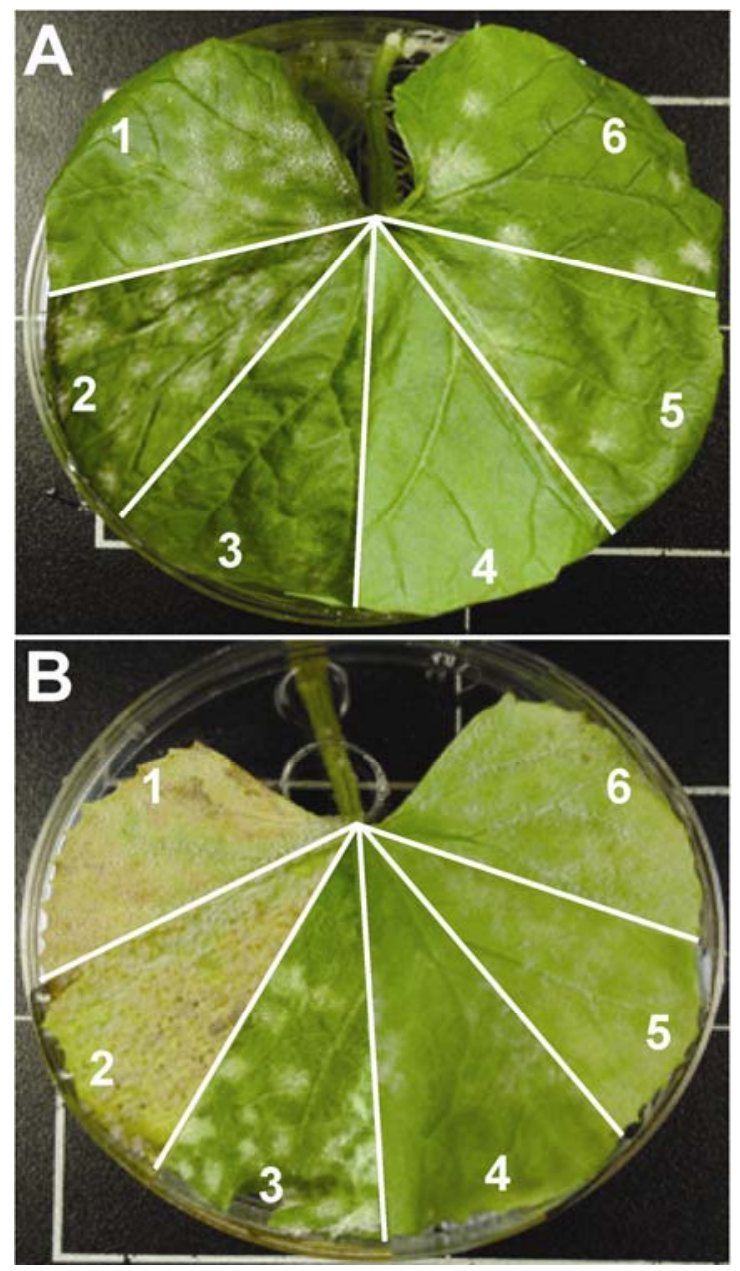

Fig. 1. Powdery mildew symptoms on melon leaves following treatments with butanolic cell-free filtrates of the antagonistic strain Bacillus subtilis UMAF6639. Treatments are 1, untreated control; 2, nutrient broth control; 3 , washed cells from stationary-phase; 4 , cell-free filtrate nondiluted; 5 and 6, cell-free filtrates 1:4- and 1:16-fold diluted, respectively. Panels are compositions of photographs of leaves inoculated with conidia of Podosphaera fusca and treated as described, taken 7 (A) and 16 (B) days after treatments. 
ity of the supernatants was stable at high temperatures (50 to $100^{\circ} \mathrm{C}$ ) and resistant to enzymatic degradation (pronase or proteinase K), all of which are well known characteristics associated with the lipopeptide antibiotics produced by Bacillus spp. (Katz and Demain 1977; Lin et al. 1998a; Stein 2005). Compared with untreated controls, when they were subjected to extremely acidic $\mathrm{pH}(\mathrm{pH} 2)$, a large precipitation occurred with a consequent lost of antifungal activity in the soluble phase; however, the supernatant activity could be restored by immediately dissolving the precipitates in neutral phosphate-buffered saline. It is interesting to note that acidic precipitation is a typical feature of lipopeptides, which often is used in purification protocols (Ohno et al. 1992). Furthermore, as previously shown, antifungal activity was efficiently extracted with n-butanol, suggesting the presence of a hydrophobic moiety in the compound which also is typical of Bacillus lipopeptides. In water solution, however, ultrafiltration tests showed that the antifungal activity was always retained in the filter, suggesting that the active molecule was of a molecular size higher than 3 $\mathrm{kDa}$. Both features are typical of biosurfactants and the latter is the result of their aggregational behavior as supramolecular micelles in water (Lin et al. 1998b). Taken together, these results demonstrated that lipopeptides could be the compounds responsible for the antifungal activity exhibited by the $B$. subtilis biocontrol strains.

\section{Identification of lipopeptides of $B$. subtilis.}

In order to identify the compounds responsible for antifungal activity, methanolic fractions from the butanolic extracts of cell-free culture filtrates of the four $B$. subtilis strains were separated initially in silica thin-layer chromatography (TLC) sheets, using purified iturin A, fengycin, and surfactin as standards (data not shown). The four B. subtilis strains produced spots with $R_{f}$ values similar to fengycin $\left(R_{f}=0.09\right)$, iturin $A$ $\left(R_{f}=0.3\right)$, and surfactin $\left(R_{f}=0.7\right)$. Likewise, when the methanolic extracts were analyzed by reverse-phase high-performance liquid chromatography (RP-HPLC), three main groups of peaks were observed at elution times comparable with those observed for standard lipopeptides; therefore, they were tentatively named in order of elution as LP-a, LP-b, and LP-c for further analysis (data not shown).
For purification of the antifungal compounds, methanolic extracts were fractioned by Flash chromatography followed by semi-preparative RP-HPLC, using a method previously developed for these families of lipopeptides. To verify the purity of different fractions, analytical RP-HPLC was performed. An example of the results obtained corresponds to strain UMAF6639, which is shown in Figure 2.

For an accurate characterization of the different purified compounds, mass spectra were recorded by matrix-assisted laser desorption-ionization time of flight mass spectrometry (MALDI-TOF-MS). The mass spectra of LP-a showed a series of mass number of $\mathrm{m} / \mathrm{z}=1,030$ to 1,074 for all strains; those of LP-b, $\mathrm{m} / \mathrm{z}=1,017$ to 1,101 for strains UMAF8561 and UMAF6614, $\mathrm{m} / \mathrm{z}=1,034$ to 1,095 for UMAF6639, or $\mathrm{m} / \mathrm{z}=$ 1,021 to 1,049 for UMAF6619; and those of LP-c, $m / z=1,435$ to 1,499 for all strains. An example of these results is shown for the strain UMAF6639 (Fig. 2).

For all fractions, the Fourier transform-infrared spectrum (FT-IR) analysis showed bands in the range of 1,630 to 1,680 $\mathrm{cm}^{-1}$, resulting from the stretching mode of the CO-N bond (amide I band), and at 1,570 to $1,515 \mathrm{~cm}^{-1}$, resulting from the deformation mode of the $\mathrm{N}-\mathrm{H}$ bond combined with $\mathrm{C}-\mathrm{N}$ stretching mode (amide II band), both indicating the presence of a peptide component; and also bands at 2,855 to $2,960 \mathrm{~cm}^{-1}$, resulting from typical $\mathrm{CH}$ stretching vibration in the alkyl chain. For the fractions LP-a and LP-c, a shoulder also was observed at $1,730 \mathrm{~cm}^{-1}$ due to the lactone carbonyl absorption typical for surfactin and fengycin families of lipopeptides (data not shown).

When the amino acid compositions were determined, it was found that the fraction LP-a contained Asp, Glu, Val, and Leu in a ratio of 1:1:1:4; fraction LP-b comprised Asp, Ser, Glu, Pro, and Tyr in a ratio of 3:1:1:1:1 for strain UMAF6639 and Asp, Ser, Glu, Pro, Tyr, and Thr in a ratio of $2: 1: 1: 1: 1: 1$ for the rest of the strains; and fraction LP-c was composed of Thr, Glu, Pro, and Ala or Val, Ile, Tyr, and Orn in a ratio of $1: 3: 1: 1: 1: 2: 1$, valine being observed only in the fraction corresponding to strain UMAF6639.

The amino acid sequences were determined by electrospray ionization ion trap mass spectrometry (ESI-MS-MS). As an example, spectra obtained for the fractions LP-a, LP-b, and

Table 2. Biochemical characterization of the antifungal activity of Bacillus subtilis supernatants ${ }^{\mathrm{Z}}$

\begin{tabular}{|c|c|c|c|c|}
\hline \multirow[b]{2}{*}{ Culture filtrates } & \multicolumn{4}{|c|}{ B. subtilis strains } \\
\hline & UMAF6614 & UMAF6619 & UMAF6639 & UMAF8561 \\
\hline \multicolumn{5}{|l|}{ Heat treatments } \\
\hline Untreated & 22 & 18 & 24 & 23 \\
\hline $50^{\circ} \mathrm{C}, 15 \mathrm{~min}$ & 22 & 18 & 24 & 23 \\
\hline $75^{\circ} \mathrm{C}, 15 \mathrm{~min}$ & 22 & 18 & 24 & 22 \\
\hline $100^{\circ} \mathrm{C}, 15 \mathrm{~min}$ & 22 & 18 & 24 & 22 \\
\hline \multicolumn{5}{|c|}{ Enzymatic degradation } \\
\hline Untreated & 26 & 19 & 24 & 24 \\
\hline Pronase & 26 & 19 & 24 & 24 \\
\hline Proteinase $\mathrm{K}$ & 26 & 18 & 24 & 24 \\
\hline \multicolumn{5}{|l|}{ pH tolerance } \\
\hline Untreated & 25 & 21 & 26 & 26 \\
\hline Acid, $\mathrm{pH}=2$ & 23 & 20 & 24 & 20 \\
\hline Basic, $\mathrm{pH}=12$ & 14 & 0 & 19 & 16 \\
\hline \multicolumn{5}{|c|}{ Organic phase after extraction with organic solvents } \\
\hline Untreated & 26 & 18 & 25 & 20 \\
\hline n-Butanol & 26 & 19 & 25 & 20 \\
\hline Chloroform & 0 & 0 & 0 & 0 \\
\hline \multicolumn{5}{|l|}{ Ultrafiltration } \\
\hline Untreated & 24 & 19 & 24 & 24 \\
\hline$>3-\mathrm{kDa}$ fraction & 26 & 19 & 29 & 30 \\
\hline$<3-\mathrm{kDa}$ fraction & 0 & 0 & 0 & 0 \\
\hline
\end{tabular}

${ }^{\mathrm{z}}$ Antifungal activity was evaluated after different treatments by an in vitro bioassay against Botrytis cinerea. Antifungal activity measured as diameter (in millimeters) of inhibition zone 15 days after incubation. Each value represents the mean of three independent experiments. 
LP-c from strain UMAF6639 are given (Fig. 2). Sequences deduced for these fractions were similar to those corresponding to surfactin, iturin A, and fengycin, respectively. For the other strains, the fractions LP-a, LP-b, and LP-c corresponded to the sequences expected for surfactin, bacillomycin, and fengycin, respectively.

All together, these results showed that the four B. subtilis strains simultaneously produced, in liquid cultures, surfactin, with a number of carbon atoms in the fatty acid moiety of C13-C15, and fengycin C14-C18, together with iturin A C14C15 (strain UMAF6639), bacillomycin D C14-C16 and bacillomycin L C17 (strains UMAF8561 and UMAF6614), or bacillomycin L C14-C17 (strain UMAF6619).

\section{Inhibitory effect of purified lipopeptides on $P$. fusca conidia germination and in planta detection of lipopeptides.}

Once lipopeptides present in the culture filtrates of the $B$. subtilis strains were identified, purified fractions of the different lipopeptides detected were used to study their inhibitory effect on $P$. fusca conidia germination. Inhibition assays were carried out on disks of zucchini cotyledons that were exposed to lipopeptide concentrations of $1 \mathrm{mg} / \mathrm{ml}$ and conidia germination was evaluated by bright field microscopy after $48 \mathrm{~h}$ of incubation. The results obtained are shown in Figure 3. As can be noted, bacillomycin (Fig. 3C) showed the strongest effect on germination, inducing $67 \%$ of inhibition, followed by fengycin (Fig. 3E) and iturin A (Fig. 3D), which produced inhibitions of 53 and $42 \%$, respectively. By contrast, surfactin (Fig. $3 \mathrm{~F})$ had no significant effect on germination according to Fisher's least significant difference test $(P=0.05)$, causing $9.5 \%$ of inhibition.

To test the hypothesis that production of lipopeptides in planta could be responsible for the suppression of powdery mildew symptoms, lipopeptides were recovered from melon leaves infected with $P$. fusca conidia and treated with washed cells of $B$. subtilis UMAF6614, UMAF6639, or UMAF8561, and analyzed by analytical RP-HPLC (Fig. 4). As shown, 5 days after application of bacteria, peaks corresponding to bacillomycin, iturin A, and fengycin were detected, whereas surfactin peaks stayed close to the detection threshold and were undetectable. Twelve days after application, however, it was very difficult to identify single peaks, which became practically undetectable, especially in the case of strain UMAF8561

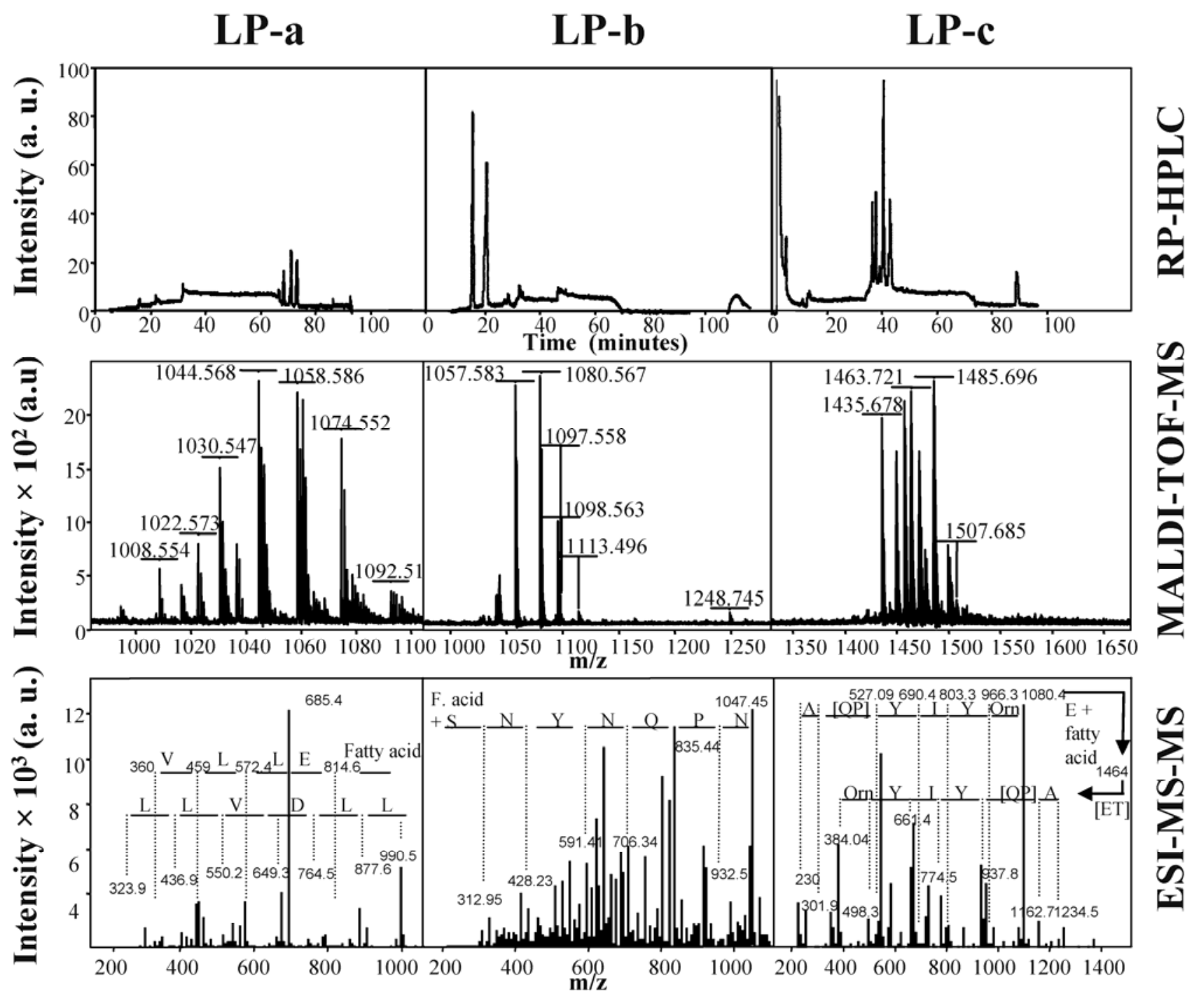

Fig. 2. Characterization and identification of lipopeptides occurring in butanolic extracts from liquid cultures of the antagonistic Bacillus subtilis strain UMAF6639. Peaks obtained on an analytical reverse-phase high-performance liquid chromatography (RP-HPLC) (detection at $214 \mathrm{~nm}$ ) for purified fractions LP-a, LP-b, and LP-c, previously fractioned by flash chromatography followed by (semi)-preparative RP-HPLC. Mass spectra scored for the purified fractions LP-a, LP-b, and LP-c. Fragmentation spectra observed by electrospray ionization ion trap mass spectrometry (ESI-MS-MS) and amino acid sequences and fatty acid compositions deduced from the parental peaks 1008.7 (LP-a, surfactin), 1065.4 (LP-b, iturin A), and 1464 (LP-c, fengycin). 
(data not shown). This decrease in lipopeptide levels always was correlated with outbreaks of powdery mildew disease.

Biological control analysis

of lipopeptide-deficient $B$. subtilis transformants.

Site-directed mutagenesis analysis focused to determine the contribution of the different lipopeptides in the antagonism of $B$. subtilis toward $P$. fusca was carried out with strains UMAF6614 and UMAF6639, which produced different lipopeptide profiles. Based on the available gene sequences governing the synthesis of bacillomycin, fengycin, and iturin A, a set of suitable primers were designed to obtain the proper DNA fragments to construct the corresponding disruption vectors (discussed below). The resulting transformants were grown in medium optimal for lipopeptide production for 4 days at $37^{\circ} \mathrm{C}$. Analysis of butanolic extracts from supernatants of several transformants by TLC (data not shown) and analytical RP-HPLC (Fig. 5) confirmed the expected phenotypes. The derivative transformants disrupted in the $f e n B$ gene completely lost the ability to produce fengycin. Likewise, the disruption of bamA and $i t u D$ genes resulted in transformants unable to produce bacillomycin and iturin A, respectively. In addition, polymerase chain reaction (PCR) and Southern hybridization analyses confirmed the correct insertion of the plasmids within the target gene sequences (data not shown). Two single-copy transformants of each strain and phenotype were selected for further analysis (Table 3).

The ability of the different mutants to arrest growth of $P$. fusca was evaluated by two set of experiments, one using vegetative cells and the other using butanolic extracts of cell-free supernatants. With vegetative cells (Table 4), whereas UMAF6614 and UMAF6639 wild types reduced disease up to $64 \%$, their derivative mutants deficient in bacillomycin and iturin A lost completely their ability to suppress powdery mildew disease ( 0 to $5 \%$ disease reduction), and the mutants deficient in fengycin achieved disease reductions of 8 to $12 \%$. In all cases, disease symptoms showed by transformants were significantly different from those observed for wild types and statistically

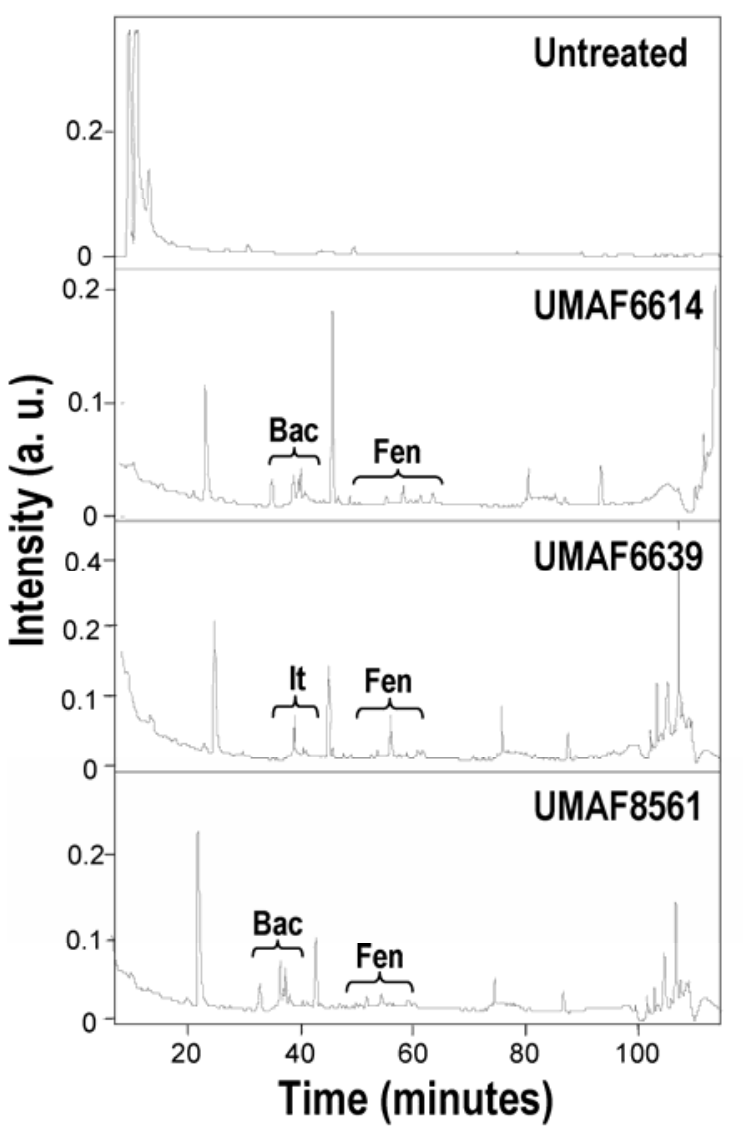

Fig. 4. In planta detection of lipopeptides by analytical reverse-phase high-performance liquid chromatography (RP-HPLC). Melon plants were infected with powdery mildew and treated with Bacillus subtilis strains UMAF6614, UMAF6639, and UMAF8561. Lipopeptides were recovered from melon leaves 5 days after application of $B$. subtilis. Noninfected and nontreated leaves were used as controls (untreated). Peaks corresponding to bacillomycin (Bac), fengycin (Fen), and iturin A (It) are indicated. Detection at $214 \mathrm{~nm}$.
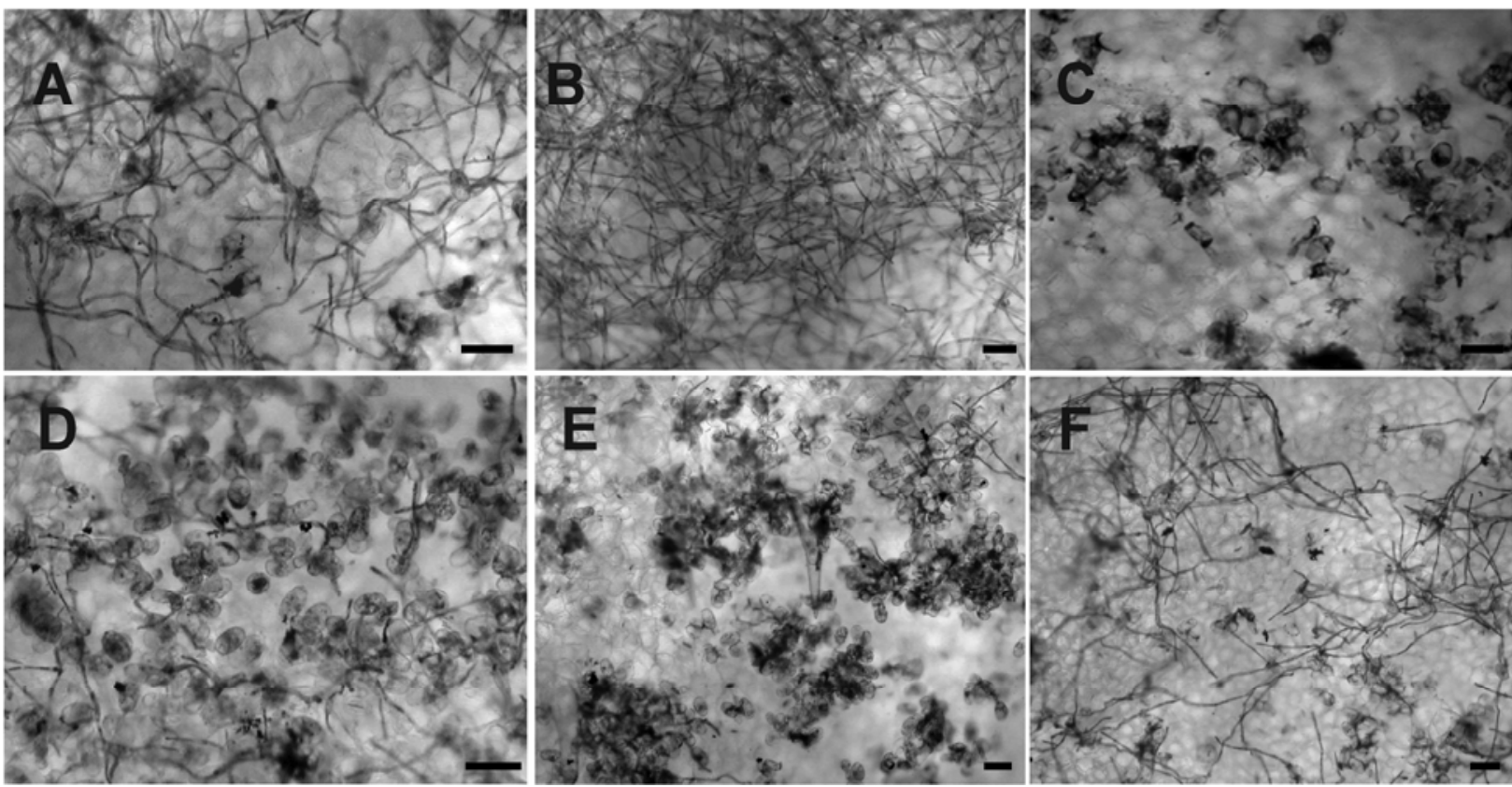

Fig. 3. Effect of purified lipopeptides on Podosphaera fusca conidia germination. Disks of zucchini cotyledons were treated with the corresponding lipopeptide at $1 \mathrm{mg} / \mathrm{ml}$ and the percentage of conidia germination was evaluated by bright field microscopy after $48 \mathrm{~h}$ of incubation. Representative pictures showing the effect of each lipopeptide treatment are given. $\mathbf{A}$ and $\mathbf{B}$, untreated controls; $\mathbf{C}, \mathbf{D}, \mathbf{E}$, and $\mathbf{F}$, disks treated with bacillomycin, fengycin, iturin A, and surfactin, respectively. Bars: $40 \mu \mathrm{m}$. 


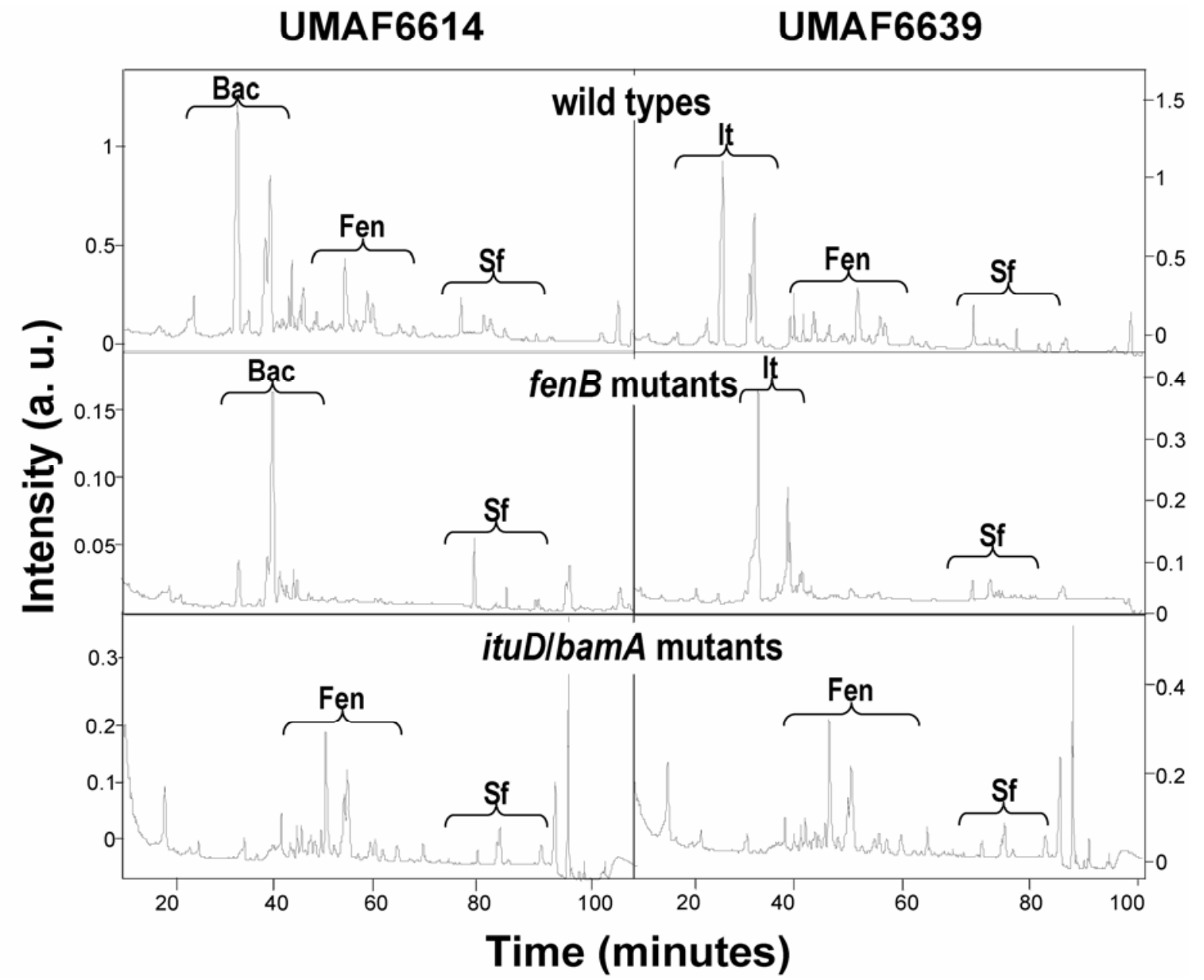

Fig. 5. Reverse-phase high-performance liquid chromatography (RP-HPLC) analysis of lipopeptides produced by Bacillus subtilis antagonistic strains UMAF6614 and UMAF6639 and their derivative mutants in liquid cultures. From strains UMAF6639 and UMAF6614, mutants impaired in production of fengycin (fenB mutants) and iturin A (ituD mutants) or bacillomycin (bamA mutants), respectively, were constructed. Peaks corresponding to iturin (It), bacillomycin (Bac), fengycin (Fen), and surfactin (Sf) are indicated. Detection at $214 \mathrm{~nm}$.

Table 3. Microorganisms and plasmids used in this study

\begin{tabular}{|c|c|c|}
\hline Strains or plasmids & Relevant characteristics $^{\mathrm{x}}$ & Reference \\
\hline \multicolumn{3}{|l|}{ Fungi } \\
\hline Botrytis cinerea CECT 2850 & Isolated from saffron bulb & CECTY $^{y}$ \\
\hline Podosphera fusca SF48 & Isolated from melon plants & Fernández-Ortuño et al. 2006 \\
\hline \multicolumn{3}{|l|}{ Bacterial strains and mutants } \\
\hline Bacillus subtilis UMAF6614 & Producer of bacillomycin, fengycin, and surfactin & Romero et al. 2005 \\
\hline B. subtilis UMAF6619 & Producer of bacillomycin, fengycin, and surfactin & Romero et al. 2005 \\
\hline B. subtilis UMAF6639 & Producer of iturin A, fengycin, and surfactin & Romero et al. 2005 \\
\hline B. subtilis UMAF8561 & Producer of bacillomycin, fengycin and surfactin & Romero et al. 2005 \\
\hline 6614::bamA-1 & UMAF6614 bamA::pCR-Bac; bacillomycin deficient & This study \\
\hline 6614::bamA-2 & UMAF6614 bamA::pCR-Bac; bacillomycin deficient & This study \\
\hline 6614::fenB-1 & UMAF6614 fenB::pFen2-2; fengycin deficient & This study \\
\hline 6614::fenB-2 & UMAF6614 fenB::pFen2-2; fengycin deficient & This study \\
\hline 6639::ituD-1 & UMAF6639 ituD::pItu2-2; iturin A deficient & This study \\
\hline 6639::ituD-2 & UMAF6639 ituD::pItu2-2; iturin A deficient & This study \\
\hline 6639::fenB-1 & UMAF6639 fenB::pFen2-2; fengycin deficient & This study \\
\hline 6639::fenB-2 & UMAF6639 fenB::pFen2-2; fengycin deficient & This study \\
\hline \multicolumn{3}{|c|}{$e^{2}$} \\
\hline pCR-Bac & pCR2 1 carrying bamA::Km; $\mathrm{Ap}^{\mathrm{r}}, \mathrm{Km}^{\mathrm{r}}$ & This study \\
\hline pFen2-2 & pUC18 carrying fen $B:: \mathrm{Cm} ; \mathrm{Ap}^{\mathrm{r}}, \mathrm{Cm}^{\mathrm{r}}$ & Romero et al. 2006 \\
\hline pItu2-2 & pUC18 carrying ituD ::Spc; $\mathrm{Ap}^{\mathrm{r}}, \mathrm{Spc}^{\mathrm{r}}$ & Romero et al. 2006 \\
\hline
\end{tabular}

${ }^{\mathrm{x}} \mathrm{Ap}^{\mathrm{r}}=$ ampicillin resistance, $\mathrm{Cm}^{\mathrm{r}}=$ cloramphenicol resistance, and $\mathrm{Km}^{\mathrm{r}}=$ kanamycin resistance.

${ }^{\mathrm{y}}$ CECTY $=$ Spanish type culture collection.

${ }^{\mathrm{z}}$ Integrative plasmids containing gene sequences from B. subtilis UMAF6614 or UMAF6639. 
comparable with untreated controls. Similar results were observed when the level of conidia production was evaluated.

The above results were supported when bioassays of growth inhibition using butanolic extracts of cell-free filtrates were carried out (Table 5). For strain UMAF6614, whereas the wildtype supernatant still showed some antifungal activity $(27 \%$ of inhibition) 16-fold diluted, extracts from fengycin and bacillomycin mutants lost their activity at 4 - to 8 -fold dilutions. A similar tendency also was observed for strain UMAF6639. Wild-type extracts were very active at 16 -fold dilution (82\% of inhibition); however, at the same dilution, supernatants from fengycin mutants completely lost their activity, whereas extracts from iturin A mutants showed no inhibition 4- to 8-fold diluted.

Table 4. Severity of powdery mildew symptoms and sporulation degree of Podosphaera fusca on melon leaves following treatments with vegetative cells from Bacillus subtilis wild-type strains and their lipopeptide deficient derivative mutants ${ }^{\mathrm{x}}$

\begin{tabular}{lcccc}
\hline & \multicolumn{2}{c}{ Disease symptoms } & \multicolumn{2}{c}{ Sporulation } \\
\cline { 2 - 5 } Treatments & Severity & Reduction $^{\mathbf{y}}$ & Conidia & Reduction $^{\mathbf{z}}$ \\
\hline Untreated & $72 \mathrm{a}$ & $\ldots$ & $1,233 \mathrm{a}$ & $\ldots$ \\
UMAF6614 & $29 \mathrm{~b}$ & 60 & $396 \mathrm{~b}$ & 68 \\
Bacillomycin mutants & & & & \\
6614::bamA-1 & $68 \mathrm{a}$ & 5 & $1,121 \mathrm{a}$ & 9 \\
$\quad$ 6614::bamA-2 & $72 \mathrm{a}$ & 0 & $1,201 \mathrm{a}$ & 2 \\
Fengycin mutants & & & & \\
6614::fenB-1 & $65 \mathrm{a}$ & 10 & $1,051 \mathrm{a}$ & 14 \\
6614::fenB-2 & $63 \mathrm{a}$ & 12 & $1,065 \mathrm{a}$ & 14 \\
UMAF6639 & $26 \mathrm{~b}$ & 64 & $308 \mathrm{~b}$ & 75 \\
Iturin A mutants & & & & \\
6639::ituD-1 & $70 \mathrm{a}$ & 3 & $1,150 \mathrm{a}$ & 7 \\
$\quad$ 6639::ituD-2 & $69 \mathrm{a}$ & 4 & $1,148 \mathrm{a}$ & 7 \\
Fengycin mutants & & & & \\
6639::fenB-1 & $63 \mathrm{a}$ & 12 & $1,034 \mathrm{a}$ & 16 \\
6639::fenB-2 & $66 \mathrm{a}$ & 8 & $1,056 \mathrm{a}$ & 14 \\
\hline
\end{tabular}

${ }^{\mathrm{x}}$ Severity (assessed as percentage of leaf area covered by powdery mildew) and sporulation (conidia $\mathrm{cm}^{-2}$ ) were scored 16 days after treatments. Percentages of disease and sporulation reductions achieved by treatments also are indicated. Data within each column are the means of three independent experiments. Values followed by the same letter are not significantly different at $P=0.05$ according to Fisher's least significant difference test.

${ }^{y}$ Percentage of disease reduction referred to values of leaf area covered by powdery mildew on untreated leaves.

${ }^{\mathrm{z}}$ Percentage of sporulation reduction referred to values of conidia production on untreated leaves.

\section{DISCUSSION}

Several reports have described Bacillus strains worthy to be used as biocontrol agents of plant diseases (Shoda 2000). One of the most convincing properties contributing to that suggestion is the amazing battery of antibiotic compounds synthesized that exhibit a wide antimicrobial spectrum, the ability to modify attachment of other microorganisms to different surfaces and to contribute to the survival of the bacillus cells in their habitat (Stein 2005). In our study, the supernatants of four $B$. subtilis strains have proved to suppress cucurbit powdery mildew disease at levels similar to those previously reported for vegetative cells (Romero et al. 2004). The comprehensive chemical analysis of culture filtrates proved the occurrence of three different lipopeptide antibiotics, surfactin, fengycin, and iturin A or bacillomycin, compounds well known for their strong antifungal effect against different necrotrophic phytopathogenic fungi (Asaka and Shoda 1996; Vanittanakom et al. 1986). These findings together with the fact that the biocontrol efficiency of each strain was closely correlated with the lipopeptide production yield, strongly supported the relevant role of antibiosis as a major factor involved in the protective effect of these strains, and were in agreement with previous reports that had pointed out that biotrophic fungi, such as $P$. fusca, could be efficiently targeted by antibiotic-producing microorganisms (Avis et al. 2002).

Additional assays carried out with purified lipopeptide fractions showed that iturin A, bacillomycin, and fengycin retained the highest antifungal activities, whereas surfactin showed a limited action. In this sense, although the direct action of antimicrobials in the bacterial antagonism in vitro has been well characterized, evidence of the in situ production of these antimicrobials in their corresponding environments to correlate them with the biocontrol ability has long been a constraint (Raaijmakers et al. 2002). In this study, we have been able to detect iturin A, bacillomycin, and fengycin on melon leaves treated with two strains of $B$. subtilis. The occurrence of lipopeptides 5 days after bacterial treatments clearly supported the in vitro observations of their inhibitory effect upon $P$. fusca conidia germination and development because, when lipopeptides were hardly detected, as occurred 12 days after bacterial application, outbreaks of powdery mildew symptoms occurred, as previously shown in other systems (Asaka and Shoda 1996; Ongena et al. 2005). These results demonstrated a clear contribution of iturin $\mathrm{A}$, bacillomycin, and fengycin in the antagonism of $B$. subtilis toward $P$. fusca.

Table 5. Effect of butanolic extracts of cell-free culture filtrates of Bacillus subtilis wild-type strains and their lipopeptide deficient derivative mutants on Podosphaera fusca growth inhibition

\begin{tabular}{|c|c|c|c|c|c|}
\hline \multirow[b]{2}{*}{ Treatments } & \multicolumn{5}{|c|}{ Dilution factor of lipopeptide-enriched solutions ${ }^{\mathrm{z}}$} \\
\hline & 1:0 & 1:1 & $1: 3$ & 1:7 & 1:15 \\
\hline UMAF6614 & $94 \pm 4$ & $69 \pm 6$ & $50 \pm 8$ & $42 \pm 8$ & $27 \pm 7$ \\
\hline \multicolumn{6}{|l|}{ Bacillomycin mutants } \\
\hline 6614::bamA-1 & $39 \pm 9$ & $4 \pm 1$ & $0 \pm 0.1$ & $0 \pm 0.1$ & $0 \pm 0.1$ \\
\hline 6614::bamA-2 & $53 \pm 15$ & $35 \pm 10$ & $11 \pm 0.1$ & $4 \pm 2$ & $0 \pm 0.1$ \\
\hline \multicolumn{6}{|l|}{ Fengycin mutants } \\
\hline 6614::fenB-1 & $55 \pm 15$ & $32 \pm 10$ & $15 \pm 9$ & $0 \pm 0.1$ & $0 \pm 0.1$ \\
\hline 6614::fenB-2 & $60 \pm 20$ & $29 \pm 8$ & $7 \pm 3$ & $0 \pm 0.1$ & $0 \pm 0.1$ \\
\hline UMAF6639 & $100 \pm 0.1$ & $100 \pm 0.1$ & $98 \pm 4$ & $94 \pm 3$ & $82 \pm 9$ \\
\hline \multicolumn{6}{|l|}{ Iturin A mutants } \\
\hline 6639::ituD-1 & $25 \pm 9$ & $11 \pm 0.1$ & $0 \pm 0.1$ & $0 \pm 0.1$ & $0 \pm 0.1$ \\
\hline 6639::ituD-2 & $23 \pm 7$ & $14 \pm 2$ & $8 \pm 4$ & $0 \pm 0.1$ & $0 \pm 0.1$ \\
\hline \multicolumn{6}{|l|}{ Fengycin mutants } \\
\hline 6639::fenB-1 & $91 \pm 3$ & $60 \pm 7$ & $38 \pm 11$ & $15 \pm 6$ & $0 \pm 0.1$ \\
\hline 6639::fenB-2 & $88 \pm 7$ & $44 \pm 7$ & $20 \pm 10$ & $12 \pm 6$ & $0 \pm 0.1$ \\
\hline
\end{tabular}

${ }^{\mathrm{z}}$ Percentage of inhibition of $P$. fusca growth referred to values of leaf area covered by powdery mildew recorded after 14 days of incubation. Data represent the means \pm standard deviation from 10 disks per treatment. The experiment was repeated three times. 
To clarify the involvement of antimicrobials in the biocontrol performance, additional evidence is always offered by molecular analysis either reducing or avoiding biocontrol activity by mutagenesis (Raaijmakers et al., 2002) or enhancing the antimicrobial production, modifying biosynthetic or regulatory genes (Leclere et al. 2005). For mutational analysis, only strains UMAF6614 and UMAF6639, showing good and reproducible biocontrol performance and different lipopeptide profiles, were included. A site-directed mutagenesis strategy to inactivate a single locus was set up to construct a collection of mutants with different combinations of lipopeptide production. Based on the antifungal activity previously demonstrated for each purified lipopeptide, our main attention was focused on the disruption of iturin A, bacillomycin, and fengycin production. The biocontrol results obtained in bioassays using vegetative cells showed the expected role for iturin A, bacillomycin, and fengycin in the disease suppression ability of these strains, as revealed by the complete loss of biocontrol. The growth inhibition assays using butanolic extracts from supernatants of the different mutants confirmed those data, and allowed us to conclude that iturin A, bacillomycin, and fengycin are indispensable for the biocontrol ability of these strains of $B$. subtilis, at least on $P$. fusca. Furthermore, the fact that extracts from mutants producing only iturin $\mathrm{A}$ and surfactin still retained a considerable high antifungal activity suggested the possible occurrence of a synergistic antifungal effect between both lipopeptides, as previously reported (Koumoutsi et al. 2004; Magnet-Dana et al. 1992). This point could be clarified by construction of double mutants impaired in the production of both surfactin and iturin A lipopeptides.

Early studies have emphasized the fact that the antimicrobial effect of lipopeptides not only rely on their chemical structure but also on the sterol content of the plasma membrane in the target fungi, due to a buffering effect of sterols on the increase in membrane fluidity caused by the fatty acids (Avis et al. 2002; Latoud et al. 1990). In this sense, the low sterol content of conidia of powdery mildew fungi, compared with other fungal plant pathogens and the presence of certain amounts of cholesterol molecules in their membranes (Loeffler et al., 1992) could explain the high susceptibility exhibited by $P$. fusca conidia to these compounds.

The B. subtilis strains UMAF6614 and UMAF6639 have proven to be excellent candidates to be used in the biological control of cucurbit powdery mildew elicited by $P$. fusca (Romero et al. 2004). In this work, we have provided experimental evidence represented by the antifungal effect of cellfree supernatants as well as the presence of the antifungal compounds bacillomycin, fengycin, iturin A, and surfactin in liquid cultures and in bacterial-treated leaves, which supported the early assumption of antibiosis as the main mode of action displayed by these strains to manage the disease. Additionally, a differential role of the lipopeptides in the biocontrol performance has been established by mutational analysis, confirming a major contribution of the iturin (bacillomycin and iturin A) and fengycin families of lipopeptides in the antagonism of $B$. subtilis toward $P$. fusca, the suppression of conidia germination determining to a large extent the subsequent development of the pathogen. Work to determine the ultrastructural damage induced by these compounds on $P$. fusca is currently underway.

\section{MATERIALS AND METHODS}

\section{Microorganisms and culture conditions.}

The fungi, bacterial strains, and plasmids used in this study are listed in Table 3. Routinely, fresh bacterial cultures were obtained from frozen stocks before each experiment. B. subtilis strains were grown in nutrient agar (NA), nutrient broth (NB), NB supplemented with $1 \%$ glucose, or in medium optimal for lipopeptide production (MOLP) (Ahimou et al. 2000) at $37^{\circ} \mathrm{C}$. Escherichia coli was grown in Luria-Bertani broth (LB) at $37^{\circ} \mathrm{C}$. Antibiotics, when required, were added to the culture media at the following concentrations: ampicillin, $100 \mu \mathrm{g} / \mathrm{ml}$; chloramphenicol, $5 \mu \mathrm{g} / \mathrm{ml}$; spectinomycin, $100 \mu \mathrm{g} / \mathrm{ml}$; kanamycin, $10 \mu \mathrm{g} / \mathrm{ml}$; and erythromycin, $5 \mu \mathrm{g} / \mathrm{ml}$.

The plant-pathogenic fungus $B$. cinerea CECT 2850 was grown in potato dextrose agar (PDA) at $25^{\circ} \mathrm{C}$. Isolate SF48 of $P$. fusca race 1 was maintained in vitro on zucchini cotyledons as described elsewhere (Pérez-García et al. 2001).

\section{Antifungal activity assays with $B$. subtilis supernatants.}

To determine the relationship between growth and production of antifungal compounds, $B$. subtilis strains were grown in Erlenmeyer flasks $(250 \mathrm{ml})$ containing $100 \mathrm{ml}$ of $\mathrm{NB}$ or NB supplemented with $1 \%$ glucose or with $50 \mathrm{mM}$ diethyl malonate, a sporulation inhibitor added at the end of the log phase. Incubation was carried out in an orbital shaker for several days at $30^{\circ} \mathrm{C}$ and $80 \mathrm{rpm}$. Culture samples of $2 \mathrm{ml}$ were taken at various time points and examined for number of vegetative cells and spores and antifungal activity. For the latter, because $P$. fusca cannot be cultured in artificial media, a growth inhibition assay in 24-well microplates using $B$. cinerea was set up. Cell-free filtrates from the different liquid cultures were obtained by centrifugation at $2,500 \times g$ for $15 \mathrm{~min}$ followed by filtration through $0.2-\mu \mathrm{m}$ cellulose nitrate filters. Microplate wells then were filled with a 1:1 mixture of PDA and the corresponding dilution of the cell-free filtrates and, after solidification, a 5-mm-diameter plug of $B$. cinerea mycelium, obtained from PDA plates grown at $25^{\circ} \mathrm{C}$ for 4 days, was placed at the center of each well. After 5 days of incubation at $25^{\circ} \mathrm{C}$, antifungal activity was determined by measuring the diameter of the fungal colony and comparing with NB controls.

The cell-free filtrates also were tested for their ability to reduce $P$. fusca growth in a bioassay using the detached leaf method previously described (Romero et al. 2003). Bacterial cultures were grown on NB supplemented with $1 \%$ glucose as described above. After 5 days of incubation, cells were removed by centrifugation at $2,500 \times g$ for $15 \mathrm{~min}$, and supernatants were extracted with n-butanol as described earlier (Yazgan et al. 2001). Once the butanol layer was completely evaporated, the residue was dissolved in sterile distilled water. For biocontrol assays, an isolate of $P$. fusca race 1 and 3- to 4-week-old melon plants (Cucumis melo, cv. Rochet) were used (PérezGarcía et al. 2001). Inoculation of leaves and incubation conditions as well as evaluation of disease progress and sporulation degree were carried out as described previously (Romero et al. 2003).

\section{Characterization, purification, and identification of antifungal compounds.}

For biochemical characterization of the responsible compounds, the antifungal activity of cell-free filtrates was subjected to stability tests, which included resistance to extreme $\mathrm{pH}$ and thermal conditions, enzymatic degradation, solubility in organic solvents, and estimation of molecular size (Yazgan et al. 2001). After the different treatments, antifungal activity was evaluated using a bioassay against $B$. cinerea similar to the technique of dual culture analysis previously described (Romero et al. 2004; Yoshida et al. 2001) but replacing bacterial colonies by culture filtrates (Arrebola et al. 2003), and measuring the diameter of the inhibition zone 15 days after incubation.

For purification and identification of the antimicrobial compounds produced by B. subtilis, the strains were grown in Erlenmeyer flasks containing MOLP. The extraction of the antifun- 
gal compounds was performed as indicated above, n-butanol layers were collected and evaporated to dryness under vacuum, and residues dissolved in methanol. The methanolic fractions were analyzed first by TLC (Razafindralambo et al. 1993) and afterward by RP-HPLC, using an analytical Zorbax C18 column, $4.6 \mathrm{~mm}$ in diameter by $150 \mathrm{~mm}$ long (Agilent, Palo Alto, CA, U.S.A.) and solutions of $0.05 \%$ trifluoroacetic acid in acetonitrile and in milliQ water, with a flow rate of $1 \mathrm{ml} / \mathrm{min}$.

The different groups of peaks from butanolic extracts were fractionated by Flash chromatography as described earlier (Deleu et al. 1999; Razafindralambo et al. 1993), followed by (semi)-preparative RP-HPLC using a Vydak C18 column, 22 $\mathrm{mm}$ in diameter by $250 \mathrm{~mm}$ long (Separations Group, Hesperia, CA, U.S.A.) and the solutions mentioned above with a flow rate of $23 \mathrm{ml} / \mathrm{min}$.

The identification of the antifungal compounds was confirmed by scoring the mass spectra contained in the purified fractions using an Ultraflex MALDI-TOF mass spectrometer (Bruker Daltonics, Billerica, MA, U.S.A.) operated in positive ion mode. The samples were prepared as previously described (Williams et al. 2002) with minor modifications. Furthermore, the FT-IR of the purified fractions was obtained as well as the amino acid compositions, as described earlier (Razafindralambo et al. 1993).

The amino acid sequences for the peptide moiety were determined by ESI-MS-MS. Briefly, samples of ring-opened lipopeptides by cleavage of the lactone bond (Williams et al. 2002) were analyzed on an Esquire 3000 Plus ion trap mass spectrometer (Bruker Daltonics) and sequences deduced by comparing the fragmentation spectra with the available databases.

\section{Microscopic analysis of $\boldsymbol{P}$. fusca conidia germination.}

Evaluation of the inhibitory effect of purified lipopeptides on $P$. fusca conidia germination was carried out following the zucchini cotyledon disk method (Fernández-Ortuño et al. 2006) with slight modifications. Leaf disks were taken from zucchini cotyledons, disinfected with $\mathrm{HgCl}_{2}$ for $1 \mathrm{~min}$, and rinsed twice in sterile distilled water. The purified lipopeptide solutions were adjusted to $1 \mathrm{mg} / \mathrm{ml}$ and $3 \mathrm{ml}$ were poured into sterile six-well plates. The cotyledon disks were placed in these solutions upside down and incubated overnight at $25^{\circ} \mathrm{C}$ and a 16-h photoperiod. After incubation, the disks were transferred onto agar plates (Álvarez and Torés 1997) and the upper sides of the disks were inoculated with conidia of $P$. fusca with the aid of an eyelash. After $48 \mathrm{~h}$ of incubation at $22^{\circ} \mathrm{C}$ and a 16-h photoperiod, disks were cleared and stained as previously reported (Hückelhoven and Kogel 1998; Lyngkjaer and Carver 1999) and examined under a bright-field microscope. The percentage of inhibition of conidia germination then was calculated in relation to untreated controls.

\section{Recovery of lipopeptides from melon leaves.}

The bioassay was set up as previously reported (Romero et al. 2004). Leaves of melon plants of the susceptible cv. Rochet, grown under greenhouse conditions, were inoculated by spreading of a $P$. fusca spore suspension adjusted to $10^{5}$ conidia/ml. The bacterial suspensions $\left(10^{8} \mathrm{CFU} / \mathrm{ml}\right)$ were applied 4 days after pathogen challenge until run-off. Leaves from symptomless plants as well as from untreated plants were taken 5 and 12 days after application of bacteria and processed for lipopeptide recovery as described by Asaka and Shoda (1996). Briefly, the leaves were placed in $30 \mathrm{ml}$ of $0.05 \%$ trifluoroacetic acid in acetonitrile in a 50-ml Erlenmeyer flask and shaken for $1 \mathrm{~h}$. Once extracted, the samples were evaporated and the remaining precipitate was extracted with methanol for $2 \mathrm{~h}$. The extract was finally concentrated and prepared for analysis by RP-HPLC as described earlier.
Construction of $B$. subtilis mutants and analysis of transformants.

Site-directed mutagenesis was used to suppress the production of the different lipopeptides by inserting disruption vectors into selected biosynthetic genes via single-crossover homologous recombination. For construction of the integrative plasmids, DNA fragments of the genes $f e n B$, involved in fengycin production (Lin et al. 1998a); ituD, iturin A production (Tsuge et al. 2001); and bamA, bacillomycin production (Moyne et al. 2004) were obtained by PCR using specific primers and Taq polymerase (Amersham Bioscience, Uppsala, Sweden) or PWO superyield DNA polymerase (Roche, Basel, Switzerland). The amplified fragments were cloned into the SmaI-digested pUC18 plasmid and the resulting plasmids subsequently were linearized with suitable enzymes and ligated to appropriate antibiotic resistance cassettes (Guérot-Fleury et al. 1995; Romero et al. 2006). The disruption of bacillomycin synthesis was alternatively achieved by construction of the plasmid pCR-Bac, resulting from the cloning of a fragment of bamA gene into the pCR2.1 plasmid (TA Cloning Kit V; Invitrogen Ltd., Paisley, UK). E. coli transformations were performed following the calcium chloride method (Sambrook and Russell 2001) and the plasmid preparations were obtained with the High Pure Plasmid Isolation kit (Roche).

Transformation of $B$. subtilis was carried out according to the protoplast electroporation protocol previously developed (Romero et al. 2006). The lipopeptide-deficient phenotype of transformants first was evaluated by TLC and subsequently confirmed by RP-HPLC, as described above. In addition, transformants were molecularly analyzed by PCR and Southern hybridization using the antibiotic resistance cassettes or partial sequences of the target genes as probes, to confirm gene disruption and select single-copy transformants. B. subtilis chromosomal DNA was isolated with the Ultraclean Microbial DNA kit (Mobio Laboratories, Carlsbad, CA, U.S.A.). Southern hybridizations were carried out by a digoxigenin enzymelinked immunosorbent assay using a DNA labeling and detection kit (Roche) as recommended in the instruction manual.

\section{Biological control analysis of lipopeptide-deficient $B$. subtilis mutants.}

The disease-suppressive effects of vegetative cells and cellfree supernatants of the different $B$. subtilis mutants were evaluated following two different bioassays. Biocontrol trials using washed vegetative cells were performed following the melon detached-leaf method previously reported (Romero et al. 2004). Disease progression was assessed by recording disease severity as percent quantification of the leaf area covered with powdery mildew, and conidia production (Romero et al. 2003). Evaluation of antifungal activity of supernatants was carried out following the zucchini cotyledon disks method (Fernández-Ortuño et al. 2006), as mentioned previously. Butanolic extracts of cell-free culture filtrates were obtained as described above. The lipopeptide-enriched solutions were serially diluted in distilled water and $3 \mathrm{ml}$ were poured into sterile six-well plates. The cotyledon disks were placed in these solutions and incubated overnight. After incubation, the disks were transferred onto agarized medium and inoculated with $P$. fusca conidia. After 14 days of incubation at $25^{\circ} \mathrm{C}$ and a $16-\mathrm{h}$ photoperiod, disease severity and percentage of growth inhibition were calculated as previously described (Fernández-Ortuño et al. 2006).

\section{Statistical analysis.}

Data were statistically analyzed using analysis of variance, followed by Fisher's least significant difference test $(P=$ 0.05), using SPSS-software (SPSS Inc., Chicago). 


\section{ACKNOWLEDGMENTS}

This study was supported by grants from Plan Nacional de Recursos y Tecnologías Agroalimentarias from the Ministerio de Educación y Ciencia, Spain (AGL2001-1837-C02-01 and AGL2004-06056-C02-01). D. Romero was supported by a grant from the former Ministerio de Ciencia $y$ Tecnología. The amino acid sequences of lipopeptides were determined in the Proteomic Laboratory, Centro Nacional de Biotecnología (CSIC), Madrid, Spain.

\section{LITERATURE CITED}

Ahimou, F., Jacques, P., and Deleu, M. 2000. Surfactin and iturin A effects on Bacillus subtilis surface hydrophobicity. Enzyme Microb. Technol. 27:749-754.

Álvarez, B., and Torés, J. A. 1997.Cultivo in vitro de Sphaerotheca fuliginea (Schlecht. ex. Fr.), efecto de diferentes fuentes de carbono sobre su desarrollo. Bol. San. Veg. Plagas 23:283-288.

Arrebola, E., Cazorla, F. M., Durán, V. E., Rivera, E., Olea, F., Codina, J. C., Pérez-García, A., and de Vicente, A. 2003. Mangotoxin: A novel antimetabolite toxin produced by Pseudomonas syringae inhibiting ornithine/arginine biosynthesis. Physiol. Mol. Plant Pathol. 63:117-127.

Asaka, O., and Shoda, M. 1996. Biocontrol of Rhizoctonia solani damping-off of tomato with Bacillus subtilis RB14. Appl. Environ. Microbiol. 62:4081-4085.

Avis, T. J., and Bélanger, R. R. 2002. Mechanisms and means of detection of biocontrol activity of Pseudozima yeast against plant-pathogenic fungi. FEMS (Fed. Eur. Microbiol. Soc.) Yeast Res. 2:5-8.

Baehler, E., de Werra, P., Wick, L. Y., Péchy-Tarr, M., Mathys, S., Maurhofer, M., and Keel, C. 2006. Two novel Mvat-like global regulators control exoproduct formation and biocontrol activity in root-associated Pseudomonas fluorescens CHAO. Mol. Plant-Microbe Interact. 19:313-329.

Bais, H. P., Fall, R., and Vivanco, J. M. 2004. Biocontrol of Bacillus subtilis against infection of Arabidopsis roots by Pseudomonas syringae is facilitated by biofilm formation and surfactin production. Plant. Physiol. 134:307-319.

Cazorla, F. M., Dukett, S. B., Berström, E. T., Noreen, S., Odijk, R., Lugtenberg, B. J. J., Thomas-Oates, J. E., and Bloemberg, G. V. 2006. Biocontrol of avocado Dematophora root rot by antagonistic Pseudomonas fluorescens PCL1606 correlates with the production of 2-hexyl 5 propyl resorcinol. Mol. Plant-Microbe Interact. 10:79-86.

Deleu, M., Razafindralambo, H., Popineau, Y., Jacques P., Thonart, P., and Paquot, M. 1999. Interfacial and emulsifying properties of lipopeptides from Bacillus subtilis. Colloid Surf. A-Physicochem. Eng. Asp. 152:310.

del Pino, D., Olalla, L., Pérez-García, A., Rivera, M. E., García, S., Moreno, R., de Vicente, A., and Torés, J. A. 2002. Occurrence of races and pathotypes of cucurbit powdery mildew in southeastern Spain. Phytoparasitica 30:459-466.

Duitman, E. H., Hamoen, L. W., Rembold, M., Venema, G., Seitz, H., Saenger, W., Bernhard, F., Reinhardt, R., Schmidt, M., Ulrich, C., Stein, T., Leenders, F., and Vater, J. 1999. The mycosubtilin synthetase of Bacillus subtilis ATCC 6633: A multifunctional hybrid between a peptide synthetase, an amino transferase, and a fatty acid synthase. Proc. Natl. Acad. Sci. U.S.A. 96:13294-13299.

Emmert, E. A. B., and Handelsman, J. 1999. Biocontrol of plant disease: A (Gram-) positive perspective. FEMS (Fed. Eur. Microbiol. Soc.) Microbiol. Lett. 171:1-9.

Fernández-Ortuño, D., Pérez-García, A., López-Ruiz, F., Romero, D., de Vicente A., and Torés, J. A. 2006. Occurrence and distribution of resistance to QoI fungicides in populations of Podosphaera fusca in south central Spain. Eur. J. Plant Pathol. 115:215-222.

Fogliano, V., Ballio, A., Gallo, M., Woo, S., Scala, F., and Lorito, M. 2002. Pseudomonas lipodepsipeptides and fungal-cell degrading enzymes act synergistically in biological control. Mol. Plant-Microbe Interact. 15:323-333.

Guérot-Fleury, A. M., Shazand, K., Frandsen, N., and Straiger, P. 1995. Antibiotic-resistance cassettes for Bacillus subtilis. Gene 167:335-336.

Hückelhoven, R., and Kogel, K. H. 1998. Tissue-specific superoxide generation at interaction sites in resistant and susceptible near-isogenic barley lines attacked by the powdery mildew fungus (Erysiphe graminis $\mathrm{f}$. sp. hordei). Mol. Plant-Microbe Interact. 11:292-300.

Katz, E., and Demain, A. L. 1977. The peptide antibiotics of Bacillus: Chemistry, biogenesis, and possible functions. Bacteriol. Rev. 41:449474.

Kiss, L. 2003. A review of fungal antagonists of powdery mildews and their potential as biocontrol agents. Pest Manage. Sci. 59:475-483.

Kloepper, J. W., Ryu, C. M., and Zhang, S. A. 2004. Induced systemic re- sistance and promotion of plant growth by Bacillus spp. Phytopathology 94:1259-1266.

Kondoh, M., Hirai, M., and Shoda, M. 2001. Integrated biological and chemical control of damping-off caused by Rhizoctonia solani using Bacillus subtilis RB14-C and flutolanil. J. Biosci. Bioeng. 91:173-177.

Koumoutsi, A., Chen, X. H., Henne, A., Liesegang, H., Hitzeroth, G., Franke, P., Vater, J., and Borris, R. 2004. Structural and functional characterization of gene clusters directing nonribosomal synthesis of bioactive cyclic lipopeptides in Bacillus amyloliquefaciens strain FZB42. J. Bacteriol. 186:1084-1096.

Latoud, C., Peypoux, F., and Michel, G. 1990. Interaction of iturin A, a lipopeptide antibiotic, with Saccharomyces cerevisiae cells: Influence of the sterol membrane composition. Can. J. Microbiol. 36:384-389.

Leclere, V., Bechet, M., Adam, A., Guez, J. S., Wathelet, B., Ongena, M., Thonart, P., Gancel, F., Chollet-Imbert, M., and Jacques, P. 2005. Mycosubtilin overproduction by Bacillus subtilis BBG100 enhances the organism's antagonistic and biocontrol activities. Appl. Environ. Microbiol. 71:4577-4584.

Lin, G. H., Chen, C. L., Tschen, J. S., Tsay, S. S., Chang, Y. S., and Liu, S. T. 1998a. Molecular cloning and characterization of fengycin synthetase gene fenB from Bacillus subtilis. J. Bacteriol. 180:1338-1341.

Lin, S.-C., Chen, Y.-C., and Lin, Y.-M. 1998b. General approach for the development of high-performance liquid chromatography methods for biosurfactant analysis and purification. J. Chromatogr. A 825:149-159.

Loeffler, R. S. T., Butters, J. A., and Hollomon, D. W. 1992. The sterol composition of powdery mildews. Phytochemistry 31:1561-1563.

Lyngkjaer, M. F., and Carver, T. L. W. 1999. Induced accessibility and inaccessibility to Blumeria graminis f. sp. hordei in barley epidermal cells attacked by a compatible isolate. Physiol. Mol. Plant Pathol. 55:151-162.

Magnet-Dana, R., and Peypoux, F. 1994. Iturins, a special class of poreforming lipopeptides: Biological and physiological properties. Toxicology 87:151-174.

Magnet-Dana, R., Thimon, L., Peypoux, F., and Ptak, M. 1992. Surfactin/iturin A interactions may explain the synergistic effect of surfactin on the biological properties of iturin A. Biochemie 74:1047-1051.

McGrath, M. T. 2001. Fungicide resistance in cucurbit powdery mildew: Experiences and challenges. Plant Dis. 85:236-245.

Moyne, A. L., Cleveland, T. E., and Tuzun, S. 2004. Molecular characterization and analysis of the operon encoding the antifungal lipopeptide bacillomycin D. FEMS (Fed. Eur. Microbiol. Soc.) Microbiol. Lett. 234:43-49.

Nofal, M. A., and Haggag, W. M. 2006. Integrated management of powdery mildew of mango in Egypt. Crop Prot. 25:480-486.

Ohno, A., Ano, T., and Shoda, M. 1992. Production of a lipopeptide antibiotic surfactin with recombinant Bacillus subtilis. Biotechnol. Lett. 14:1165-1168.

Omar, I., O’Neill, T. M., and Rossall, S. 2005. Biological control of Fusarium crown root rot of tomato with antagonistic bacteria and integrated control when combined with the fungicide cabendazim. Plant Pathol. 55:92-99.

Ongena, M., Jacques, P., Tourè, Y., Destain, J., Jabrane, A., and Thonart, P. 2005. Involvement of fengycin-type lipopeptides in the multifaceted biocontrol potential of Bacillus subtilis. Appl. Microbiol. Biotechnol. 69:29-38.

Pérez-García, A., Olalla, L., Rivera, E., del Pino, D., Cánovas I., de Vicente, A., and Torés, J. A. 2001. Development of Sphaerotheca fusca on susceptible, resistant, and temperature-sensitive resistant cultivars. Mycol. Res. 105:1216-1222.

Raaijmakers, J. M., Vlami, M., and de Souza, J. T. 2002. Antibiotic production by bacterial biocontrol agents. Antonie Leeuwenhoek 81:53747.

Razafindralambo, H., Paquot, M., Hbid, C., Jacques, P., Destain, J., and Thonart, P. 1993. Purification of antifungal lipopeptides by reversedphase high performance liquid chromatography. J. Chromatogr. 639:8185.

Romero, D., Rivera, M. E., Cazorla, F. M., de Vicente, A., and PérezGarcía, A. 2003. Effect of mycoparasitic fungi on the development of Sphaerotheca fusca in melon leaves. Mycol. Res. 107:64-71.

Romero, D., Pérez-García, A., Rivera, M. E., Cazorla, F. M., and de Vicente, A. 2004. Isolation and evaluation of antagonistic bacteria towards the cucurbit powdery mildew fungus Podosphaera fusca. Appl. Microbiol. Biotechnol. 64:263-269.

Romero, D., Cazorla, F. M., de Vicente A., and Pérez-García, A. 2005. Biological control of Podosphaera fusca by Bacillus subtilis: Role of lipopeptide antibiotics. Page 66 in: Eighth Int. Symp. Microbiol. Aerial Plant Surfaces. Oxford, UK.

Romero, D., Pérez-García, A., Veening, J. W., de Vicente, A., and Kuipers, O. P. 2006. Transformation of undomesticated strains of Bacillus subtilis by protoplast electroporation. J. Microbiol. Meth. 66:556-559. 
Sambrook, J. and Russell, D. N. 2001. Molecular Cloning: A Laboratory Manual, 3rd ed. Cold Spring Harbor Laboratory Press, Cold Spring Harbor, NY, U.S.A.

Schallmey, M., Singh, A., and Ward, O. P. 2004. Developments in the use of Bacillus species for industrial production. Can. J. Microbiol. 50:1-17.

Shoda, M. 2000. Bacterial control of plant diseases. J. Biosci. Bioeng. $89: 515-521$

Stein, T. 2005. Bacillus subtilis antibiotics: Structures, syntheses and specific functions. Mol. Microbiol. 56:845-57.

Steller, S., Vollenbroich, D., Leenders, F., Stein, T., Conrad, B., and Hofemeister, J., Jacques, P., Thonart, P., and Vater, J. 1999. Structural and functional organization of the fengycin synthetase multienzyme system from Bacillus subtilis b213 and A1/3. Chem. Biol. 6:31-41.

Thimon, L., Peypoux, F., Wallach, J., and Michel, G. 1995. Effect of the lipopeptide antibiotic, iturin A, on morphology and membrane ultrastruture of yeast cell. FEMS (Fed. Eur. Microbiol. Soc.) Microbiol. Lett. 128:101-106.

Tsuge, K., Akiyama, T., and Shoda, M. 2001. Cloning, sequencing, and characterization of the iturin A operon. J. Bacteriol. 183:6265-6273.

Vanittanakom, N., Loeffer, W., Koch, U., and Jung, G. 1986. Fengycin-A novel antifungal lipopeptide antibiotic produced by Bacillus subtilis F29-3. J. Antibiot. 39:888-901

Vater, J., Kablitz, B., Wilde, C., Franke, P., Mehta, N., and Cameotra, S. S. 2002. Matrix-assisted laser desorption ionization-time of flight mass spectrometry of lipopeptide biosurfactants in whole cells and culture filtrates of Bacillus subtilis $\mathrm{C}-1$ isolated from petroleum sludge. Appl. Environ. Microbiol. 68:6210-6219.

Vollembroich, D., Pauli, G., Özel, M., and Vater, J. 1997. Antimycoplasma properties and application in cell culture of surfactin, a lipopeptide antibiotic from Bacillus subtilis. Appl. Environ. Microbiol. 63:44-49.

Williams, B. H., Hathout, Y., and Fenselau, C. 2002. Structural characterization of lipopeptide biomarkers isolated from Bacillus globigii. J. Mass Spectrom. 37:259-264.

Yazgan, A., Ozcengiz, G., and Marahiel, A. 2001. Tn10 insertional mutations of Bacillus subtilis that block the biosynthesis of bacilysin. Biochim. Biophys. Acta-Gene Struct. Expression 1518:87-94.

Yoshida, S., Hiradate, S., Tsukamoto, T., Hatakeda, K, and Shirata, A. 2001. Antimicrobial activity of culture filtrate of Bacillus amyloliquefaciens RC-2 isolated from mulberry leaves. Phytopathology 91:181-187.

Zitter, T. A., Hopkins, D. L., and Thomas, C. E. 1996. Compendium of Cucurbit Diseases. American Phytopathological Society Press, St. Paul, MN, U.S.A.

\section{AUTHOR-RECOMMENDED INTERNET RESOURCES}

The Bacillus Genetics Stock Center (BGSC) website: www.bgsc.org The SubtiList World-Wide Web Server: genolist.pasteur.fr/SubtiList 